Pacific Journal of Mathematic 


\title{
STABLE SEQUENCES IN PRE-ABELIAN CATEGORIES
}

\author{
YONINA S. COOPER
}

In the Pacific Journal of Mathematics, 71 (1977), Richman and Walker gave a natural definition for Ext in an arbitrary pre-abelian category. Their Theorem 4, which states that $(\alpha E) \beta=\alpha(E \beta)$ for an arbitrary sequence $E$, is in error. We show, however, that $(\alpha E) \beta=\alpha(E \beta)$ does hold for a stable exact sequence. Without Theorem 4 , the crucial step in their theory is showing that $\alpha E$ is stable if $E$ is stable. We prove this. Consequently, the theory of Richman and Walker for Ext in a pre-abelian category is valid.

1. Introduction. An additive category with kernels and cokernels is called pre-abelian. Richman and Walker [3] developed an additive bifunctor Ext from an arbitrary pre-abelian category to the category of abelian groups. The Ext introduced in [3] coincides with the standard Ext (e.g., see [2]) if the category is, in fact, abelian. This theory is subsequently used by Richman and Walker [4] in the category of valuated groups. The theory of [3] is also used in [1] to examine certain relative homological algebras and to compute certain $\operatorname{Ext}(C, A)$ in the category of finite valuated groups.

However, Theorem 4 [3, p. 523] is incorrect. Without Theorem 4 , one needs to prove that the sequence $\alpha E$ is stable if the sequence $E$ is stable. This is our Theorem 2.

We use the terminology and notation of [3]. Thus, we are working working in an arbitrary pre-abelian category. If $f: A \rightarrow B$ and $\alpha: A \rightarrow A^{\prime}$, then the pushout diagram

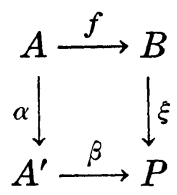

is constructed by setting $P=\operatorname{coker}(f \oplus(-\alpha)) \Delta$, where $\Delta: A \rightarrow A \oplus A$ is the diagonal map. We say that $\beta$ is the pushout of $f$ along $\alpha$. Pullbacks are obtained dually. A sequence $E$ is a diagram $A \stackrel{f}{\rightarrow}$ $B \stackrel{g}{\rightarrow} C$ such that $g f=0 . \quad E$ is left exact if $f$ is the kernel of $g$, right exact if $g$ is the cokernel of $f$, and exact if it is both left and right exact. If $\alpha: A \rightarrow A^{\prime}$, we pushout $f$ along $\alpha$ to construct the sequence $\alpha E$. 


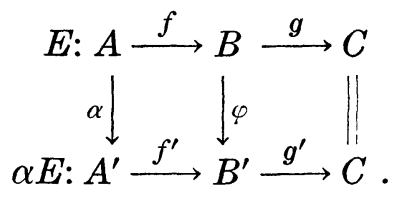

The pushout property gives the existence and uniqueness of $g^{\prime}: B^{\prime} \rightarrow$ $C$ such that $g^{\prime} f^{\prime}=0$ and $g^{\prime} \varphi=g$. We obtain $E_{\beta}$ in the dual manner for $\beta: C^{\prime} \rightarrow C$.

Richman and Walker [3, Theorem 4] assert that $(\alpha E) \beta=\alpha\left(E_{\beta}\right)$ for an arbitrary sequence $E$. This is not true, even if $E$ is exact. Consider the category of abelian $p$-groups with no elements of infinite height. Let $B$ be a direct sum of cyclic groups of order $p^{n}$ for $n=$ $1,2,3, \cdots, \bar{B}$ be the torsion subgroup of the corresponding direct product, and $G[p]=\{g \in G: p g=0\}$. Then we have

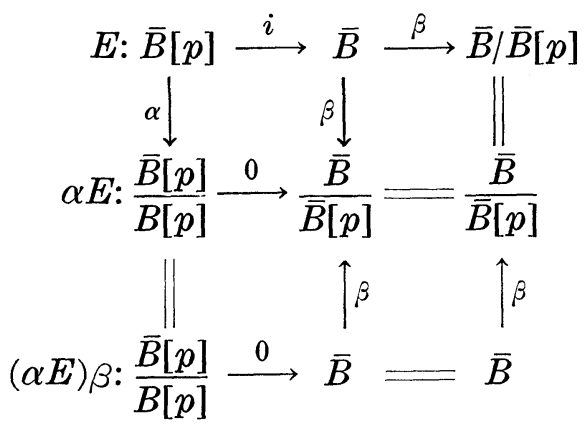

where $i$ is the injection map and $\alpha$ and $\beta$ are the coset maps. The fact that 0 is the pushout of $i$ along $\alpha$ is due to Richman and Walker [3, p. 522]. Note that $E$ is exact, but $\alpha E$ is not left exact. On the other hand, we have

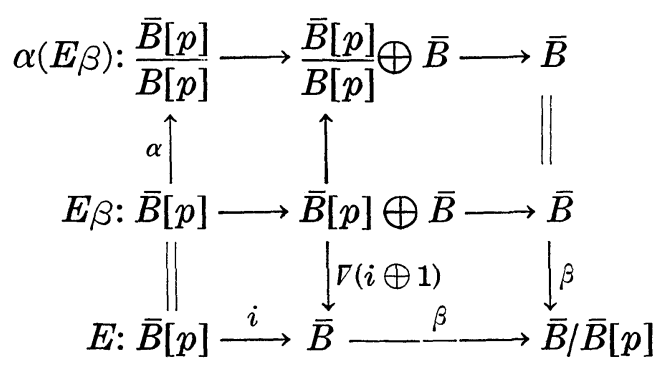

where $\nabla: \bar{B} \oplus \vec{B} \rightarrow \bar{B}$ is the codiagonal map. Hence $(\alpha E) \beta \neq \alpha\left(E_{\beta}\right)$.

2. Stable exact sequences. The example motivates following definition.

Definition (Richman and Walker [3, p. 524]). An exact sequence 
$E$ is said to be stable if $\alpha E$ and $E_{\beta}$ are exact for all maps $\alpha$ and $\beta$.

Lemma 1 (Richman and Walker [3, Theorem 5]). If $E$ is right exact, then $\alpha E$ is right exact. If $E$ is left exact, then $E_{\beta}$ is left exact.

The objective of [3] was to define Ext so that it is a functor. Thus showing that $(\alpha E) \beta=\alpha(E \beta)$ if $E$ is stable is crucial. Now there is always a morphism $\alpha\left(E_{\beta}\right) \rightarrow(\alpha E) \beta$. The problem is to get the morphism back. We now construct the morphism $\alpha\left(E_{\beta}\right) \rightarrow(\alpha E) \beta$. Consider the diagram



Construct $(\alpha E) \beta$ :

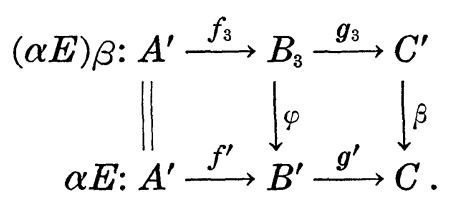

Then $\beta g_{1}=g^{\prime} \lambda \xi$ implies there exists $\delta: B_{1} \rightarrow B_{3}$ such that $g_{3} \delta=g_{1}$ and $\varphi \delta=\lambda \xi$ (since $g_{3}$ is the pullback of $g^{\prime}$ along $\beta$ ). Thus the diagram

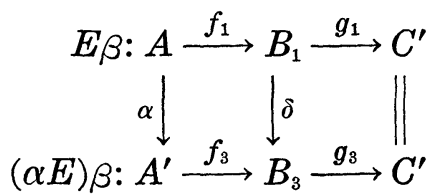

commutes since $g_{3}\left(\delta f_{1}-f_{3} \alpha\right)=g_{3} \delta f_{1}=g_{1} f_{1}=0$ and $\varphi\left(\delta f_{1}-f_{3} \alpha\right)=$ $\varphi \delta f_{1}-\varphi f_{3} \alpha=\lambda \xi f_{1}-f^{\prime} \alpha=0$ imply $f_{3} \alpha=\delta f_{1}$ (again using the fact that $g_{3}$ is a pullback). Now construct $E_{\beta} g_{3}$ and factor the morphism $(\alpha, \delta, 1)$ through $\alpha(E \beta)$, using the pushout property, to obtain the commutative diagram 




where $\varphi_{2} \varphi_{1}=\delta$. We now use this diagram to prove

THEOREM 2. Let $E: A \stackrel{f}{\rightarrow} B \stackrel{g}{\rightarrow} C$ be stable exact. Then $\alpha E$ and $E_{\beta}$ are stable exact. Furthermore, $\alpha\left(E_{\beta}\right)=(\alpha E) \beta$ for all $\alpha: A \rightarrow A^{\prime}$ and $\beta: C^{\prime} \rightarrow C$.

Proof. Now $E_{\beta}$ and $\alpha E$ are exact since $E$ is stable. And since the pull back of a pullback, is a pullback, $\left(E_{\beta}\right) \gamma=E(\beta \gamma)$ is exact. Dually $\mu(\alpha E)=(\mu \alpha) E$ is exact. Thus to show that $\alpha E$ is stable requires $(\alpha E)_{\beta}$ to be exact. Dually, the stability of $E_{\beta}$ requires the exactness of $\alpha\left(E_{\beta}\right)$. However, $g_{2}=$ coker $f_{2}$ and $f_{3}=\operatorname{ker} g_{3}$ by Lemma 1. Thus, in order to show that $\alpha E$ is stable, it only remains to show $g_{3}=\operatorname{coker} f_{3}$.

First, we show that $\varphi_{2}$ is a epimorphism. From the diagram, we observe that $g_{3} \varphi_{2} \varphi_{1} \varphi_{0}=g_{3} g_{0}$, that is, $g_{3}\left(\varphi_{2} \varphi_{1} \varphi_{0}-g_{0}\right)=0$. So there is $\gamma: X \rightarrow A^{\prime}$ such that $f_{3} \gamma=\varphi_{2} \varphi_{1} \varphi_{0}-g_{0}$ since $f_{3}=\operatorname{ker} g_{3}$. Then $f_{3} \gamma f_{0}=\varphi_{2} \varphi_{1} \varphi_{0} f_{0}=f_{3} \alpha$. So $\gamma f_{0}=\alpha$ since $f_{3}$ is a monomorphism. Now $0=\varphi_{1} \varphi_{0} f_{0}-f_{2} \alpha=\varphi_{1} \varphi_{0} f_{0}-f_{2} \gamma f_{0}=\left(\varphi_{1} \varphi_{0}-f_{2} \gamma\right) f_{0}$. So there is $\nu: B_{3} \rightarrow$ $B_{2}$ such that $\nu g_{0}=\varphi_{1} \varphi_{0}-f_{2} \gamma$ since $g_{0}=\operatorname{coker} f_{0}$. Then $\varphi_{2} \nu g_{0}=\varphi_{2} \varphi_{1} \varphi_{0}-$ $\varphi_{2} f_{2} \gamma=\varphi_{2} \varphi_{1} \varphi_{0}-f_{3} \gamma=g_{0}$. But $\varphi_{2} \nu g_{0}=g_{0}$ implies $\varphi_{2} \nu=1$ since $g_{0}$ is a cokernel and hence an epimorphism. Hence, $\varphi_{2}$ is an epimorphism since $\mu \varphi_{2}=0$ implies $\mu=\mu \varphi_{2} \nu=0$.

Suppose $\mu f_{3}=0$. Then $\mu \Phi_{2} f_{2}=0$. Since $g_{2}=$ coker $f_{2}$, there is $\eta$ such that $\eta g_{2}=\mu \varphi_{2}$. And $\eta g_{3} \varphi_{2}=\eta g_{2}=\mu \varphi_{2}$ implies $\eta g_{3}=\mu$. And if $\eta^{\prime} g_{3}=\mu$, then $\eta^{\prime} g_{2}=\eta^{\prime} g_{3} \varphi_{2}=\mu \varphi_{2}=\eta g_{2}$. And $\eta^{\prime}=\eta$ since $g_{2}$ is an epimorphism. Hence $g_{3}=\operatorname{coker} f_{3}$.

Consider the dual diagram

$$
\alpha\left(E_{\beta}\right) \longrightarrow(\alpha E) \beta \longrightarrow \alpha E \longrightarrow f_{3} \alpha E .
$$

Now the dual of the above argument gives $\varphi_{2}$ is a monomorphism and $f_{2}=\operatorname{ker} g_{2}$. Consequently, $E_{\beta}$ is stable.

Recall $\varphi_{2} \nu=1$. Then $\varphi_{2} \nu \varphi_{2}=\varphi_{2}$ implies $\nu \varphi_{2}=1$ since $\varphi_{2}$ is a monomorphism. Hence $(\alpha E) \beta=\alpha\left(E_{\beta}\right)$ in the sense that $\varphi_{2}$ is an 
isomorphism.

Ext in a pre-abelian category can now be pursued as in [3]. That is, the results and proofs of Richman and Walker [3, §3ff.] hold as stated. We conclude with the fact for an exact sequence, stability is equivalent to associativity.

THEOREM 3. An exact sequence $E$ is stable if and only if $(\alpha E) \beta=$ $\alpha\left(E_{\beta}\right)$ for all $\alpha$ and $\beta$.

Proof. Only associativity implies stability needs to proved. (The following argument is Fred Richman's.) Consider the diagrams
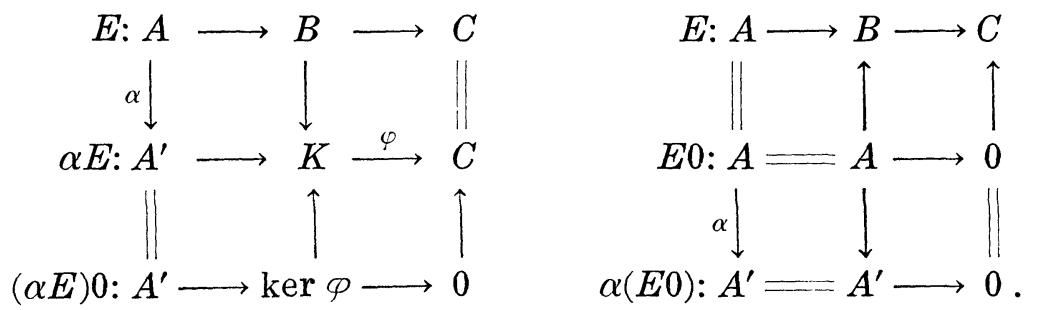

So $(\alpha E) 0=\alpha(E 0)$ implies $A^{\prime}$ maps isomorphically onto ker $\varphi$. So $\alpha E$ is exact. Similarly, $E_{\beta}$ is exact.

\section{REFERENCES}

1. Yonina Cooper, Finite valuated groups, Abelian Group Theory, Springer-Verlag, 1977, 124-139.

2. Saunders MacLane, Homology, Springer Verlag, 1975.

3. Fred Richman and Elbert A. Walker, Ext in pre-abelian catagories, Pacific J. Math., 71 (1977), 521-535.

4. - Valuated groups, J. Algebra, 56 (1979), 145-167.

Received October 16, 1978 and in revised form April 25, 1979.

UNIVERSITY OF TeXas

OdESSA, TX 79762 



\section{PACIFIC JOURNAL OF MATHEMATICS}

\section{EDITORS}

DONALD BABBITT (Managing Editor)

University of California

Los Angeles, CA 90024

Hugo RossI

University of Utah

Salt Lake City, UT 84112

C. C. MOORE and ANDREW OGG

University of California

Berkeley, CA 94720

\section{J. DugundjI}

Department of Mathematics

University of Southern California

Los Angeles, CA 90007

R. FinN and J. Milgram

Stanford University

Stanford, CA 94305

\section{ASSOCIATE EDITORS}
E. F. BeCKENBACH
B. H. Neumann
F. WoLF
K. YoSHIDA

\section{SUPPORTING INSTITUTIONS}

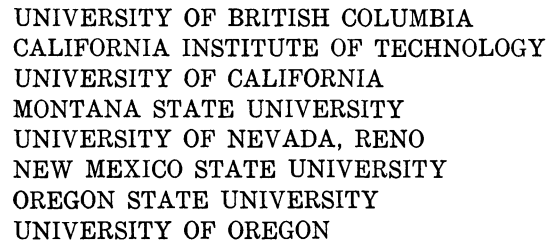

UNIVERSITY OF BRITISH COLUMBIA CALIFORNIA INSTITUTE OF TECHNOLOGY UNIVERSITY OF CALIFORNIA MONTANA STATE UNIVERSITY UNIVERSITY OF NEVADA, RENO NEW MEXICO STATE UNIVERSITY OREGON STATE UNIVERSITY UNIVERSITY OF OREGON

\author{
UNIVERSITY OF SOUTHERN CALIFORNIA \\ STANFORD UNIVERSITY \\ UNIVERSITY OF HAWAII \\ UNIVERSITY OF TOKYO \\ UNIVERSITY OF UTAH \\ WASHINGTON STATE UNIVERSITY \\ UNIVERSITY OF WASHINGTON
}

The Supporting Institutions listed above contribute to the cost of publication of this Journal, but they are not owners or publishers and have no responsibility for its content or policies.

Mathematical papers intended for publication in the Pacific Journal of Mathematics should be in typed form or offset-reproduced, (not dittoed), double spaced with large margins. Please do not use built up fractions in the text of the manuscript. However, you may use them in the displayed equations. Underline Greek letters in red, German in green, and script in blue. The first paragraph or two must be capable of being used separately as a synopsis of the entire paper. Please propose a heading for the odd numbered pages of less than 35 characters. Manuscripts, in triplicate, may be sent to any one of the editors. Please classify according to the scheme of Math. Reviews, Index to Vol. 39. Supply name and address of author to whom proofs should be sent. All other communications should be addressed to the managing editor, or Elaine Barth, University of California, Los Angeles, California, 90024.

50 reprints to each author are provided free for each article, only if page charges have been substantially paid. Additional copies may be obtained at cost in multiples of 50 .

The Pacific Journal of Mathematics is issued monthly as of January 1966. Regular subscription rate: $\$ 84.00$ a year (6 Vols., 12 issues). Special rate: $\$ 42.00$ a year to individual members of supporting institutions.

Subscriptions, orders for numbers issued in the last three calendar years, and changes of address shoud be sent to Pacific Journal of Mathematics, P.O. Box 969, Carmel Valley, CA 93924, U.S.A Old back numbers obtainable from Kraus Periodicals Co., Route 100, Millwood, NY 10546.

PUBLISHED BY PACIFIC JOURNAL OF MATHEMATICS, A NON-PROFIT CORPORATION

Printed at Kokusai Bunken Insatsusha (International Academic Printing Co., Ltd.). 8-8, 3-chome, Takadanobaba, Shinjuku-ku, Tokyo 160, Japan. 


\section{Pacific Journal of Mathematics}

\section{Vol. 91, No. 2 December, 1980}

Victor P. Camillo and Julius Martin Zelmanowitz, Dimension modules ... . . 249

Yonina S. Cooper, Stable sequences in pre-abelian categories ........... 263

Chandrakant Mahadeorao Deo and H. Ship-Fah Wong, On Berry-Esseen approximation and a functional LIL for a class of dependent random fields.........................................

H. P. Dikshit and S. N. Dubey, $|C, 1|$ summability of series associated with

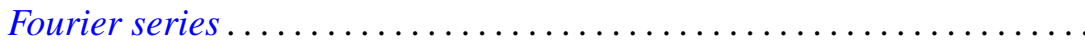

M. Edelstein, On the homomorphic and isomorphic embeddings of a semiflow into a radial flow.

Gilles Godefroy, Compacts de Rosenthal ..................... 293

James Guyker, Commuting hyponormal operators ................ 307

Thomas Eric Hall and Peter R. Jones, On the lattice of varieties of bands of

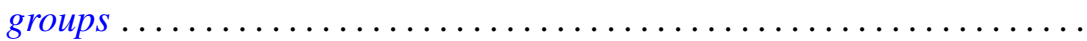

Taqdir Husain and Saleem H. Watson, Topological algebras with orthogonal Schauder bases ....................................

V. K. Jain, Some expansions involving basic hypergeometric functions of two variables. . .

Joe W. Jenkins, On group actions with nonzero fixed points ........... 363

Michael Ellsworth Mays, Groups of square-free order are scarce ........ 373

Michael John McAsey, Canonical models for invariant subspaces... 377

Peter A. McCoy, Singularities of solutions to linear second order elliptic partial differential equations with analytic coefficients by approximation methods...

Terrence Millar, Homogeneous models and decidability.

Stephen Carl Milne, A multiple series transformation of the very well poised

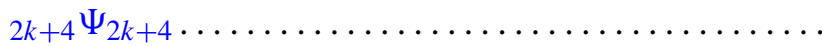

Robert Olin and James E. Thomson, Irreducible operators whose spectra are spectral sets...

Robert John Piacenza, Cohomology of diagrams and equivariant singular

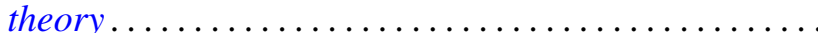

Louis Jackson Ratliff, Jr., Integrally closed ideals and asymptotic prime divisors

Robert Breckenridge Warfield, Jr., Cancellation of modules and groups and stable range of endomorphism rings.................

B. J. Day, Correction to: "Locale geometry" ...............

Stanley Stephen Page, Correction to: "Regular FPF rings" ... 